\title{
Growth of Radiologically Determined Heart Diameter, Lung Width, and Lung Length from 5-19 Years, with Standards for Clinical Use
}

\author{
GEORGE SIMON, LYNNE REID, J. M. TANNER, H. GOLDSTEIN, and \\ BERNARD BENJAMIN
}

From the Department of Experimental Pathology, Institute of Diseases of the Chest, the Department of Growth and Development, Institute of Child Health, Guilford Street, and Civil Service College, London

\begin{abstract}
Simon, G., Reid, L., Tanner, J. M., Goldstein, H., and Benjamin, B. (1972). Archives of Disease in Childhood, 47, 373. Growth of radiologically determined heart diameter, lung width, and lung length from 5-19 years, with standards for clinical use. Heart diameter, lung width, and lung length have been measured on serial chest radiographs taken at annual intervals on 84 boys and 78 girls who were tuberculosis contacts but free of disease. Most were followed from age 5 or 6 to age 15; some till age 20 . Supplementary data were available on 46 boys and 40 girls from the Harpenden Growth Study.

Centile standards for these measurements and for lung area (width $\times$ length) at ages from 6 to 19 years are presented for clinical use. Mean velocity curves are given over the same age range.

The lungs are exceptional in that the adolescent growth spurt is of similar magnitude in both boys and girls, and the girls' mean value does not exceed the boys' mean value in lung width even at the peak of the girls' spurt, as it does in all other body measurements except those of head and feet.

The age at peak velocity for lung width and heart diameter coincides with the age for peak height velocity; the peak for lung length occurs about 6 months later than that for lung width.

The heart diameter has an adolescent spurt of about equal magnitude in both sexes in these data. At age 6 , heart diameter is $78 \%$ and $81 \%$ of its adult value, respectively, in boys and girls, compared with figures of 66 to $67 \%$ for lung width, 62 to $63 \%$ for lung length, and 66 to $67 \%$ for height.

A wide variation in the level of the diaphragm was found, but by the age of 20 the diaphragm was below the anterior end of the 5 th rib in both males and females. In women no case fell below the 6th rib, but in men some $18 \%$ fell below it.
\end{abstract}

Standards for height and weight and for their increase with age have long justified their usefulness in clinical medicine as yardsticks for assessing normal development and its disturbance in disease. The need for similar yardsticks of heart and lung growth is often felt in assessing the significance of a change in heart size in a child with cardiac or pulmonary disease, or in assessing pulmonary growth in conditions such as asthma and cystic fibrosis. At present we lack such standards. Indeed we even lack knowledge of the normal growth curves of the lungs, especially at adolescence

Received 9 November 1971. and it turns out that these curves are different from those of other parts of the body.

The present study was made because a unique series of radiographs was available-a series unlikely to be seen again - of children who were radiographed yearly because they had been in contact with an older person who had sputumpositive open pulmonary tuberculosis. In the pre-streptomycin era the risk of failing to diagnose a tuberculous lesion at an early stage was considered greater than any possible risk from annual radiographs. Heart transverse diameter and lung width and length have been measured and growth charts have been constructed for boys and girls, 
giving normal centiles at each year of age. Average yearly rates of change (growth velocities) of these measurements are also given.

The only previous data on transverse heart diameter in children studied at successive ages come from the Child Research Council growth study at Denver, Colorado, at an altitude of 1524 metres. They relate to 71 boys and 57 girls in a mixed longitudinal series covering the age range 4 to 20, but reported only in a cross-sectional manner (Maresh, 1948, 1970; Bliss and Young, 1950). Lincoln and Spillman (1928) reported a cross-sectional series of 246 healthy children over the age range 2 to 13 . Jeurissen (1959a, b, 1968) reported a mixed longitudinal study of radiographic measurements of various lung segments in 1678 girls aged 1 to 18 years.

\section{Material}

Serial radiographs were available on 162 children ( 84 boys and 78 girls) seen annually, though not necessarily on or near their birthdays. Most entered the survey between 1950 and 1960, a few during 1946 to 1949.

The children came for examination because they were known to have been in contact with a tuberculous patient (Davies, 1961). Since these children came from many types of homes in London and the Home Counties, some being from professional families, they can be regarded as from above-average socioeconomic background, certainly not below it. They were healthy throughout the survey.

In 63 boys and 49 girls the radiographs began at age 5 plus (i.e. 5 to 5.9 ), and of these, 40 boys and 34 girls were followed up to, and including, age 15; 17 boys and 18 girls were still present at 16, and a few continued further. 11 boys and 9 girls entered the study at age 6 plus; 17 of these 20 were present at age 15 and 12 at age 16.10 boys and 20 girls entered at age 7 or later.

A smaller series of radiographs was available on 46 boys and 40 girls of the Harpenden Growth Study (Tanner, 1962, p. 240; Tanner, Whitehouse, and Takaishi, 1966), whose growth in other respects was followed in detail. These results were analysed in the same way as for the main series.

\section{Methods}

Radiographic. Radiographs were posteroanterior. They were taken in the standard fashion with the patient standing at an $x$-ray tube-film distance of approximately $2 \mathrm{~m}$. On each radiograph the following measurements were made as illustrated in Fig. 1.

(1) Transverse diameter of heart. The furthest projections of the heart to the right and to the left of the midline were measured and these added together to give the transverse diameter of the heart.

(2) Lung width. The transverse diameter of the thorax was measured between the inner rib surfaces

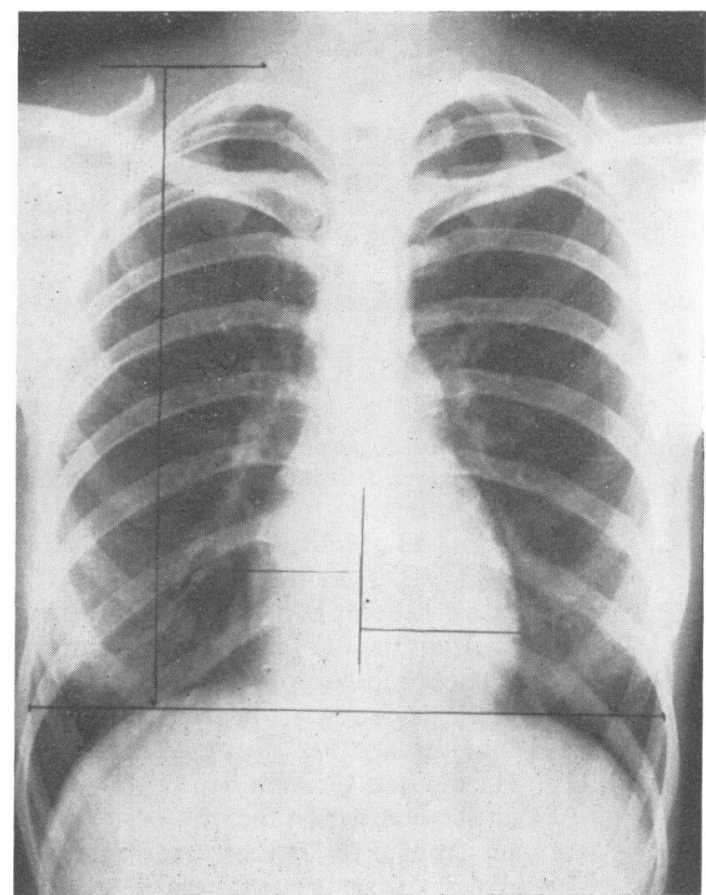

FIG. 1.-Measurements taken on radiograph: heart diameter, lung width, lung length, and level of diaphragm.

at the level of the top of the right dome of the diaphragm. This was not used to estimate cardiothoracic ratio but to estimate lung width and to confirm that the radiographs were in reasonably full inspiration.

(3) Lung length. This was estimated by drawing a horizontal line at the level of the tubercle of the first rib, since this was easy to identify. This is more important than the fact that it lies 1 to $2 \mathrm{~cm}$ above the top of the lung transradiancy, a level that is not always identifiable because of the overlap of rib shadows. From a horizontal line drawn through the tubercle of the first rib, a vertical line-midlung as judged by eye-was dropped to the top of the right dome of the diaphragm.

(4) Level of top of right dome of diaphragm. This, at least in part, is a measure of the depth of inspiration. The anterior, rather than the posterior, ribs were used since they are nearer the film and hence variation in $x$-ray tube position relative to the thorax affects diaphragm level less.

(5) Lung area was estimated as the product of measurements 2 and 3.

All measurements were made by one person, and each child's total series was measured within a period of 2 weeks. The reliability of the measurements is low compared with that of the usual anthropometric measures because the heart was radiographed at varying phases in the cardiac cycle, and the chest at varying degrees of 'maximum inspiration'. We estimate from looking at a number of radiographs taken at 6-monthly 
intervals that errors of up to $\pm 10 \%$ were not uncommon in the heart diameter and lung length. Errors in lung width appeared to be smaller. Frequently a measurement decreased over an annual period (in contrast to such measurements as height or shoulder width). The heart diameter changes were in agreement with the value of $1.5 \mathrm{~cm}$ found in adults as the limit due to cycle changes (Simon, 1968).

In all the children weight was recorded at each attendance, but height was taken too seldom for analysis.

Biometrical. A computer programme (Goldstein, 1970) was used to adjust all measurements to the nearest exact whole or half year of age, e.g. to $6 \cdot 0$ years, 6.5 years, etc. Centiles were then computed on these adjusted values, and form the basis for the graphs of Fig. 2-9. This is using all material cross-sectionally, which is relatively efficient for estimating 'distance' centiles, i.e. values at given ages.

It is not, however, the most efficient estimate, either for 'distance' or for velocity in a mixed longitudinal sample such as ours. For these we have used the Patterson (1950) procedure. This may be explained as follows. Since measurements made at successive ages (such as 1 year apart) are usually highly correlated, we may use the measurement at one age to predict fairly accurately the measurement at the following age. Hence at a given age the estimate of the mean can be

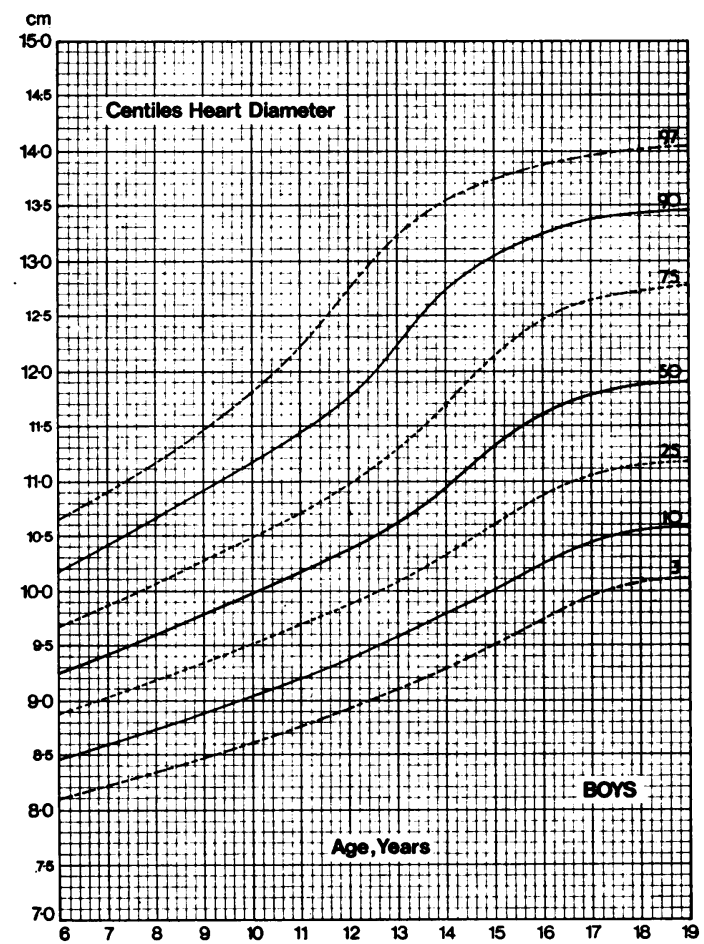

FIG. 2.-Centiles for heart diameter, boys. considered as comprising two parts. One is the mean of the measurements actually made at that age and the other is the mean of the measurements predicted from the measurements at the previous age. A suitably weighted combination of these is more efficient than the former mean used alone. We may increase efficiency further by considering the prediction back from the following age also, and indeed from all other ages. This is the procedure described by Patterson (1950) and it provides the set of most efficient distance estimates. The differences between these distance estimates also provide the most efficient estimates of change or velocity.

We have used this method for examining the mean 'distance' curves which we have compared with the values of the 50th centile obtained without applying the Patterson modification. Differences were very slight. The same applies to the mean velocities.

The distance centiles have been smoothed by eye, using the experience gained in constructing the standard British height and weight charts (Tanner et al., 1966). The mean velocity curves have also been drawn by eye in the light of the same experience. In these graphs the points have been plotted to indicate what the estimated means really were, and one typical confidence interval of \pm 2 standard errors about the mean has been drawn in to indicate the order of imprecision to which these means are subject.

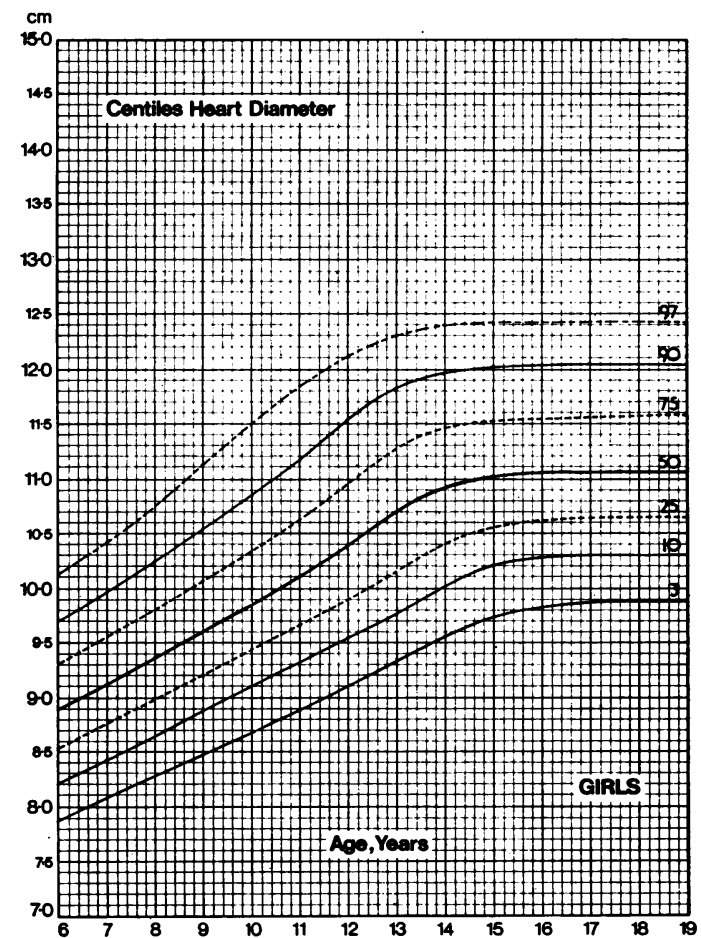

FIG. 3.-Centiles for heart diameter, girls. 


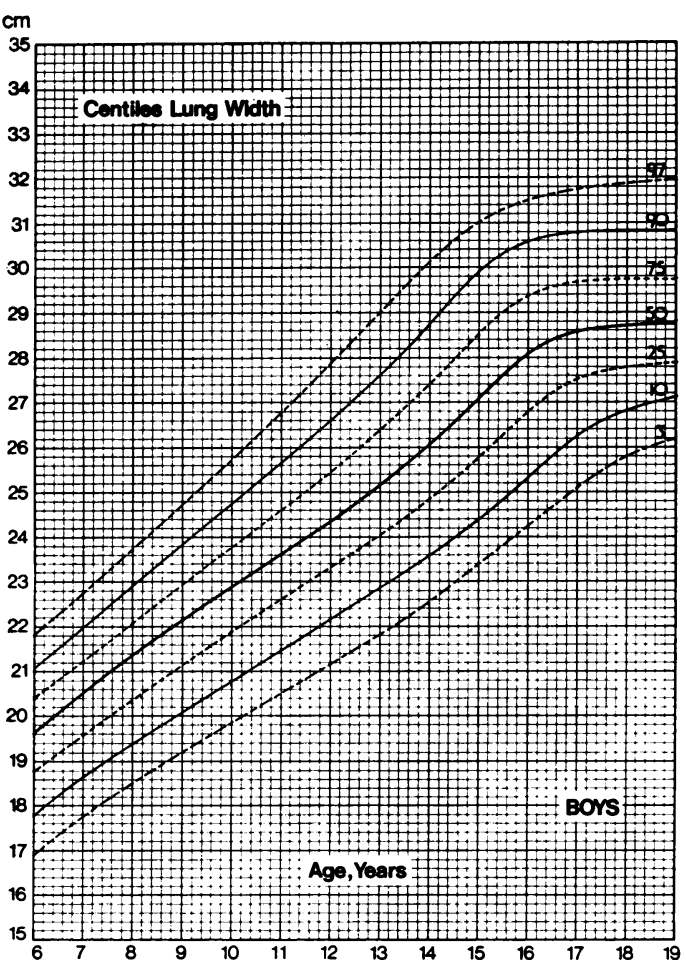

FIG. 4.-Centiles for lung width, boys.

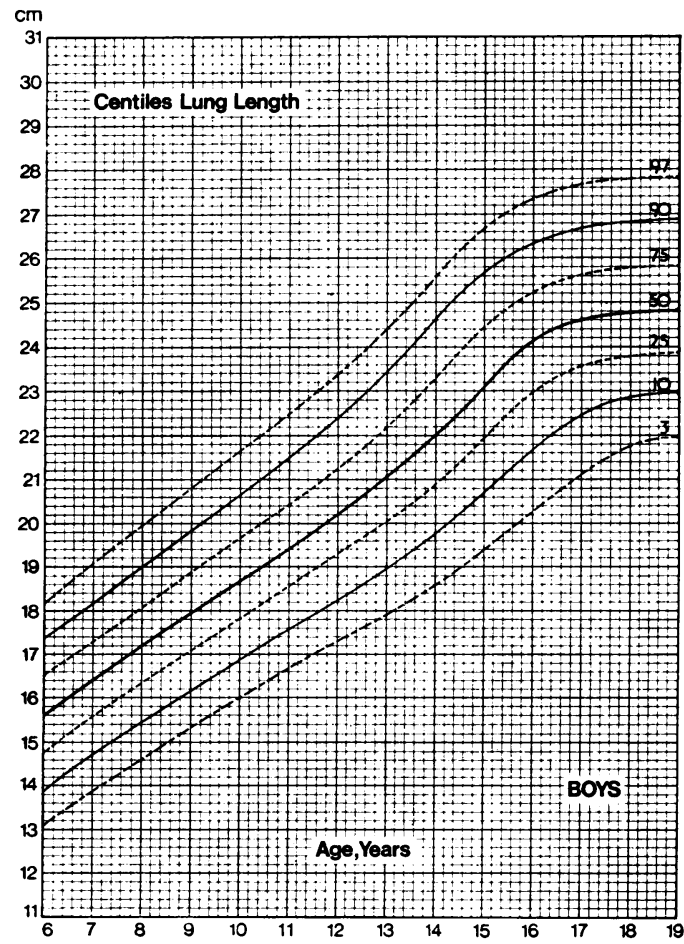

FIG. 6.-Centiles for lung length, boys.

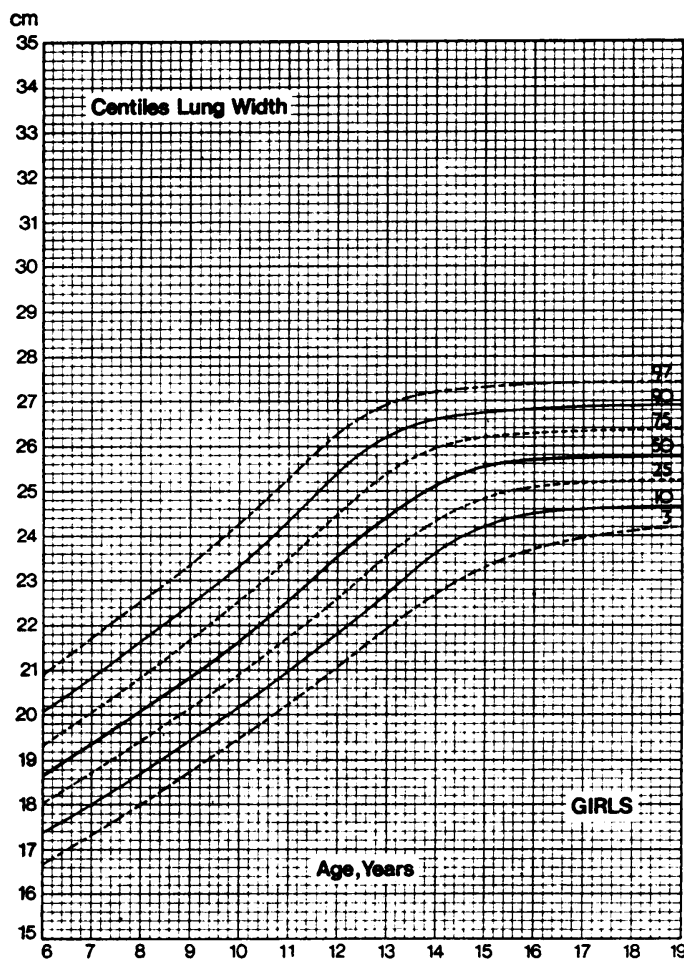

FIG. 5.-Centiles for lung width, girls.

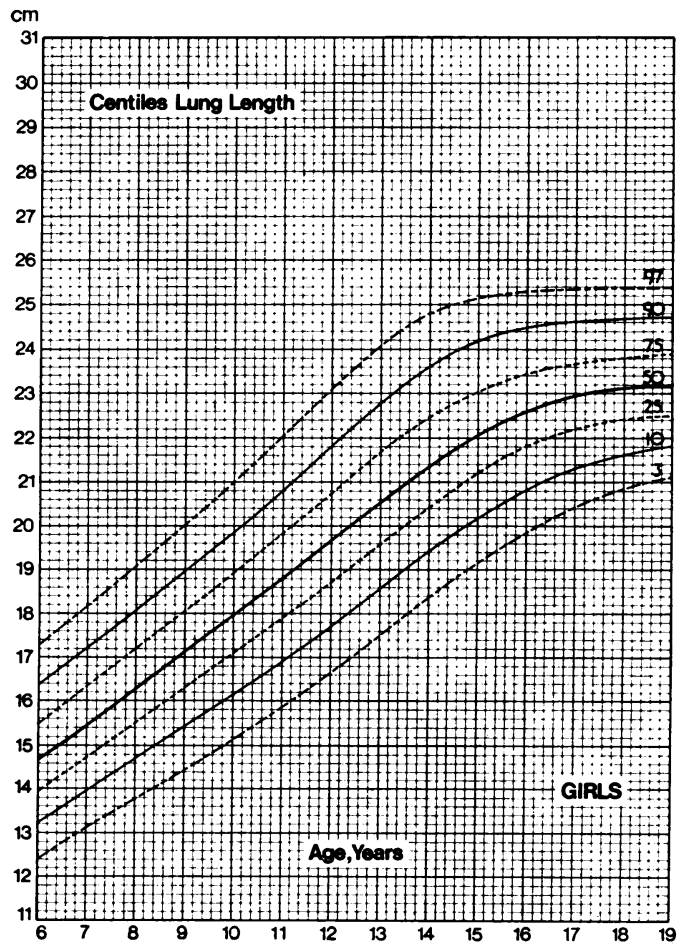

FIG. 7.-Centiles for lung length, girls.

ㅇํㅇ $+$

(

ज़

N

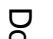

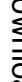

용

읔

륨

응

윽

윽

३

음

$\frac{1}{0}$

․

N

N

ज

O

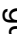

Ф

뭉

के

这 


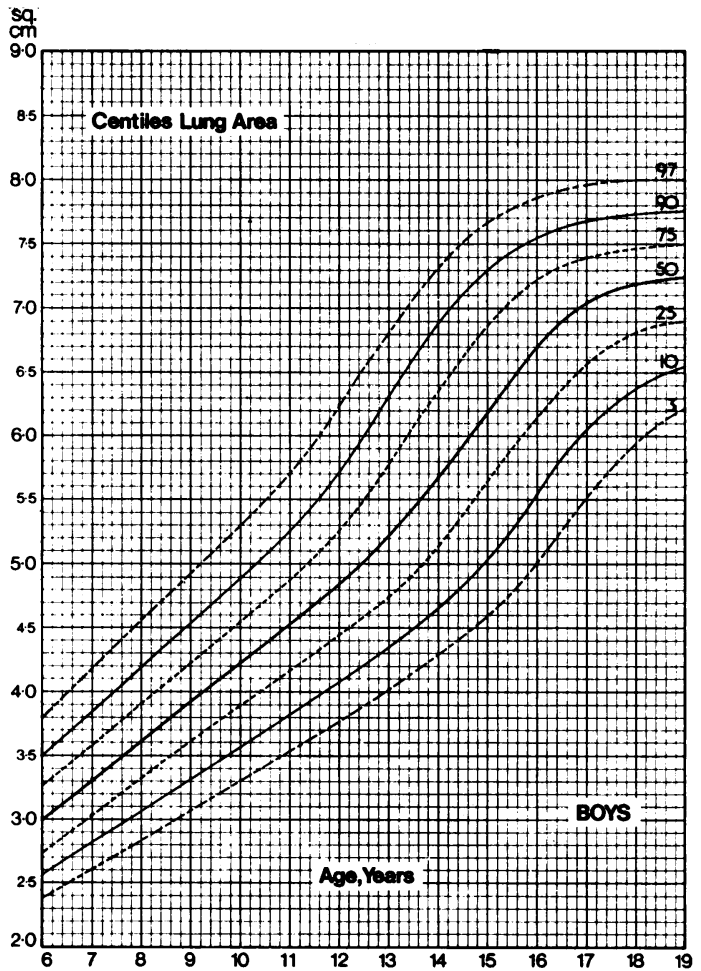

FIG. 8.-Centiles for lung area, boys.

\section{Results}

'Distance'. Fig. 2 to 9 give the 97th, 90th, $75 \mathrm{th}, 50 \mathrm{th}, 25 \mathrm{th}, 10 \mathrm{th}$, and $3 \mathrm{rd}$ centiles for heart diameter, lung length, lung width, and lung area for boys and girls. The numbers for both sexes become small after age 15, and the standards are considerably less sure above this age than below it. The numbers are also small at all ages for estimating the outside centiles (whether directly or by multiples of the SD): the position of the 50th centile is considerably more precise than those of the 3rd and 97 th centiles.

At 6 years the boys are on average larger in all three dimensions than the girls, though their variability is about the same. By the end of growth, reached on average at about age 16 in girls and 18 in boys, the boy's variability is considerably greater.

Both boys and girls show adolescent spurts in all three measurements (see Fig. 11-14 below) with the girls spurting earlier (Fig. 10). Thus, in heart diameter, the boys' mean is greater than the girls' by some $4 \%$ at age $6 \cdot 0$; at age 13 the girls

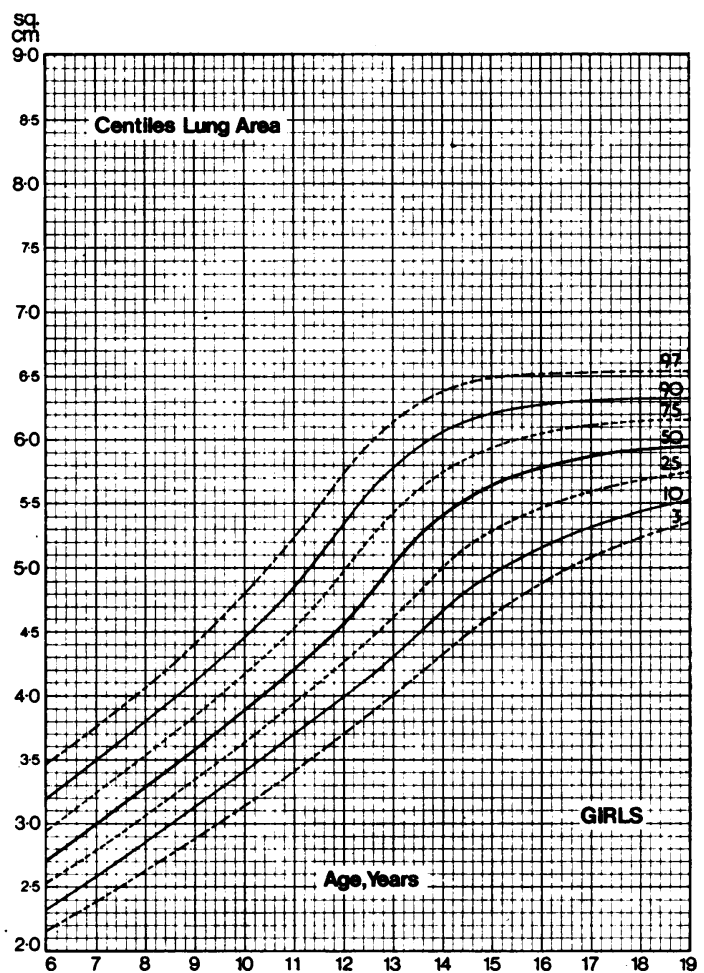

FIG. 9.-Centiles for lung area, girls.

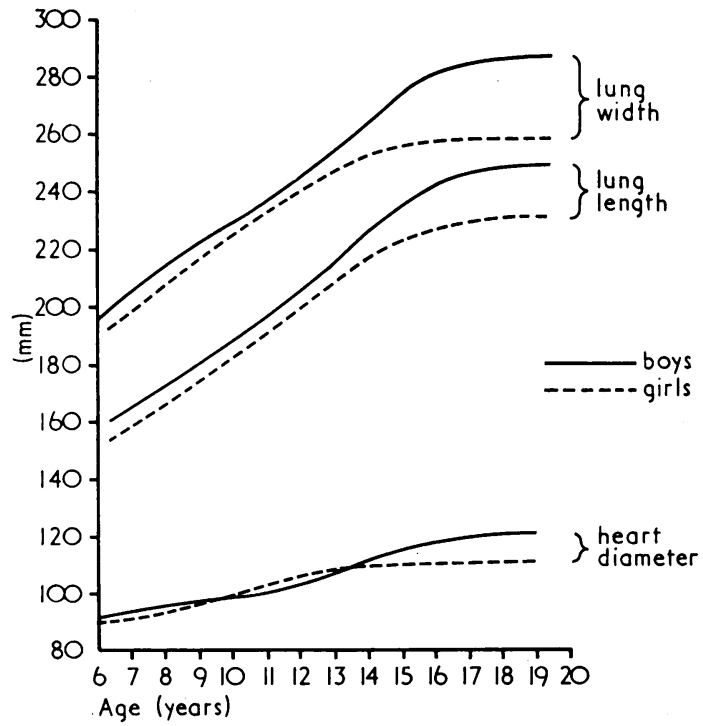

FIG. 10.-Mean values for boys and girls, age 6 to 18 . 


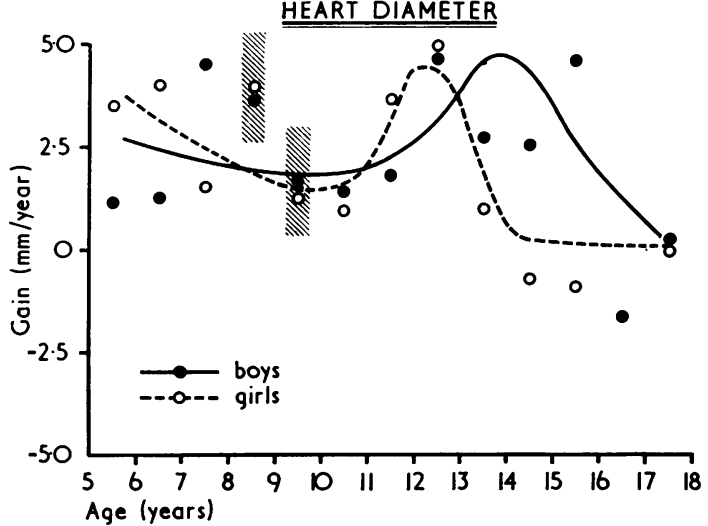

FIG. 11.-Mean velocity of heart diameter, boys and girls. Curves fitted by eye. Bars give $95 \%$ confidence interval of means, as example.

mean equals the boys' and at age 14 surpasses it. The boys' spurt then brings them to overtake the now static girls, and by age 18 the boys' mean exceeds the girls' by some $7 \cdot 5 \%$. This situation is characteristic of height and of most skeletal and muscular measurements of the body (see Tanner, 1962, p. 40). At age 6 the girls are at about the boys' 30th centile, and at age 18 at about the boys' 15 th.

The situation for lung measurements, however, is more unusual in that, as Fig. 10 shows, the girls never exceed the boys in lung width or length, nor therefore in area. At age 6, the girls' mean is about the 25th centile for boys for all three measurements; during the girls' spurt, at ages 13 and 14, it

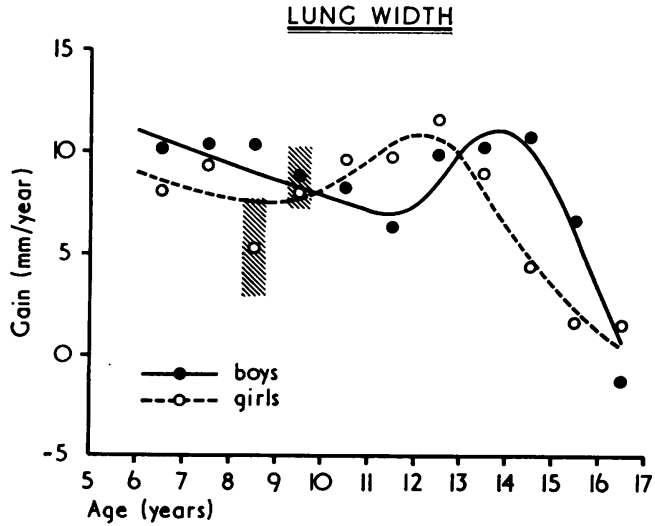

FIG. 12.-Mean velocity of lung width, boys and girls. Curves fitted by eye. Bars give $95 \%$ confidence interval of means, as example.

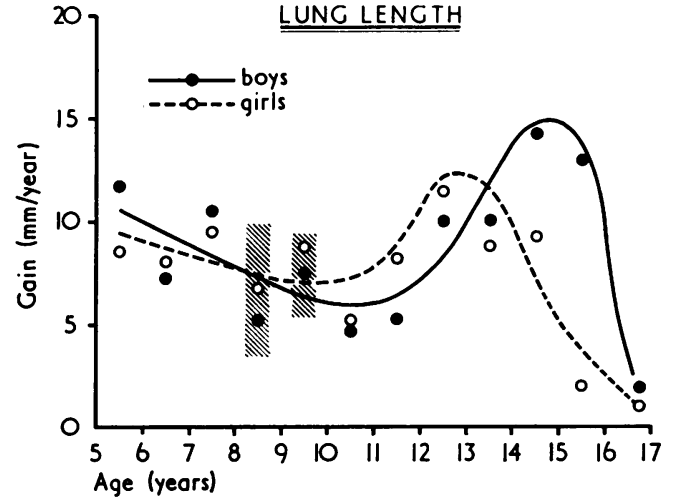

FIG. 13.-Mean velocity of lung length, boys and girls. Curves fitted by eye. Bars give $95 \%$ confidence interval of means, as example.

rises to about the boys' 40th centile and then drops to end at age 18 at the boys' 3rd centile for width and area, and 10th centile for length. Only head measurements and foot length fail to show the crossing over of girls and boys. The adult difference is about the same as for standing height, in which the girls' 50th is also at the boys' 3rd centile.

The supplementary data from the Harpenden Growth Study, computed in the same way, showed very similar curves for heart diameter. Lung width, however, did show the cross-over of girls and boys, with girls longer at ages 13 and 14; lung width did not show a cross-over but girls and boys identical at these ages.

Velocities. The dynamics of growth are most clearly shown by the mean velocities (Fig. 11-14).

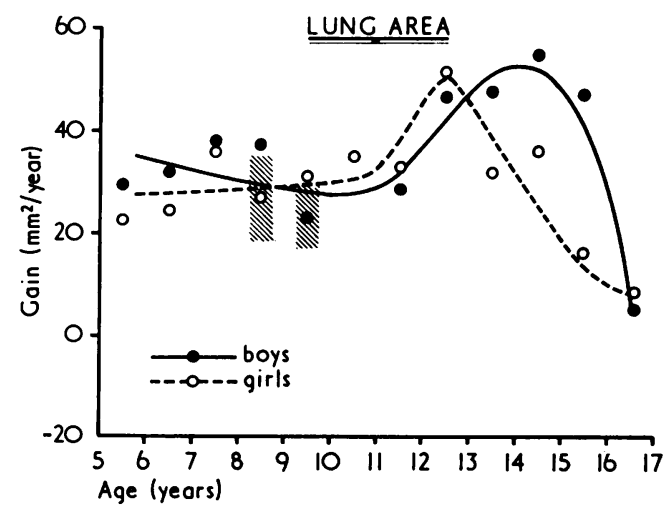

FIG. 14.-Mean velocity of lung area, boys and girls. Curves fitted by eye. Bars give $95 \%$ confidence interval of means, as example. 


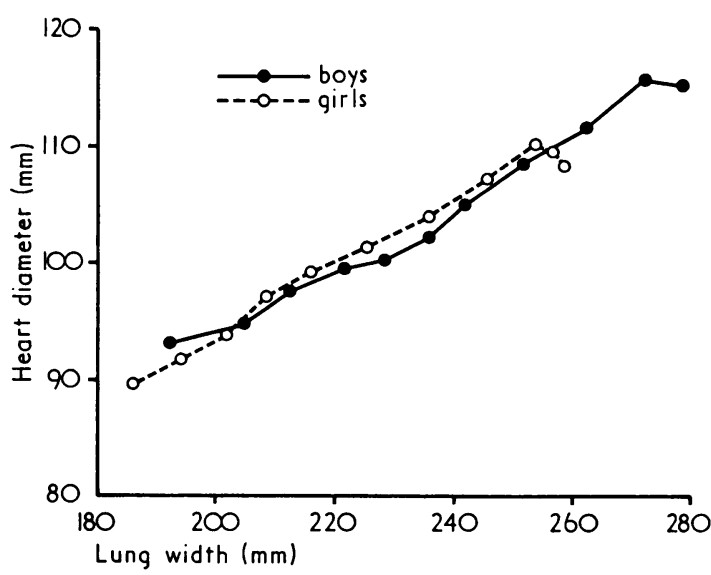

FIG. 15.-Growth in heart diameter compared with lung width.

The curves have been fitted by eye. The male diameter line is fairly arbitrary and could certainly not have been placed as it is without earlier knowledge of the course of growth in other related measurements. The other curves fit the points reasonably well.

Heart diameter velocity decreased slowly from age 6 till the adolescent spurt. The peak velocity occurred at about $12 \cdot 2$ years in girls and 13.9 in boys. These ages, within the limits of our sampling and fitting errors, are very close to the ages of peak velocity in standing height given by the British Standard charts (Tanner et al., 1966).

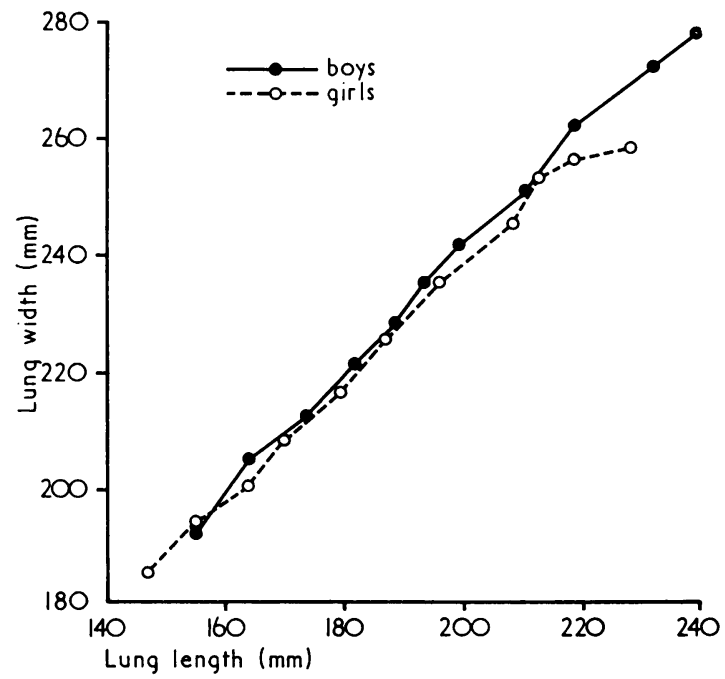

Fig. 16.-Growth in lung width compared with lung length.
The magnitude of the peaks in boys and girls appears to be the same, though these curves underestimate the true individual average peak, and in the boys underestimate slightly more (see Discussion). The situation of near-equal peaks is, all the same, unusual in body measurements.

In lung width the peaks occur at about $12 \cdot 2$ and 13.8 years also, and are again equal in magnitude in the two sexes. In lung length the peaks take place distinctly later, at about 12.8 and 14.6 years; the male peak may be fractionally greater. Lung area velocities are naturally in agreement, with peaks at $12 \cdot 4$ and $14 \cdot 0$, and a slightly greater male value.

Thus the sex difference in age of peaking is

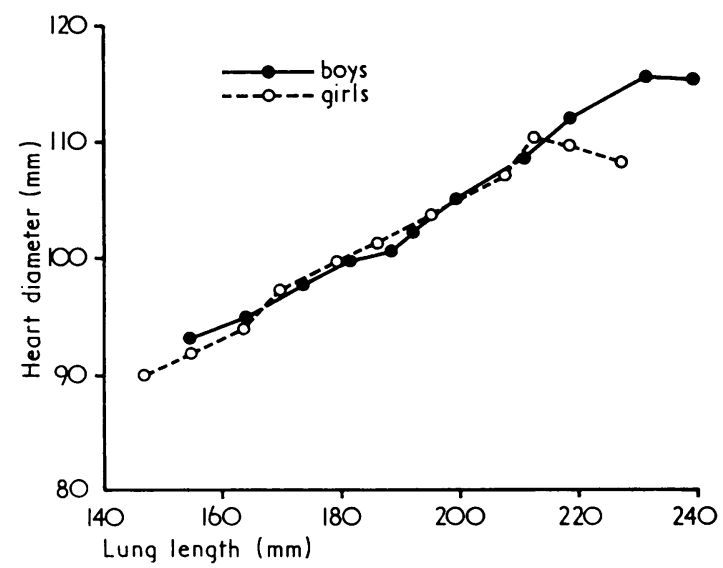

FIG. 17.-Growth in heart diameter compared with lung length.

about 1.6 years for all three measurements. This is slightly less than the standards given for height ( 2.0 years) but by an amount which could be due to sampling error.

Shape change. Fig. 15 to 17 are designed to illustrate shape changes (see Hiernaux, 1968). In Fig. 16 the mean boys' heart diameter at age 5 is plotted against the mean lung width at age 5, then the two means at age 6, and so on. The girls are plotted similarly. If the lines are parallel, the relative proportions of heart diameter and lung width do not change with age in either sex, and if coincident, the proportions are the same in the two sexes. If the lines diverged at adolescence, then it would indicate that in one sex there was a disproportionate growth in one of the pair measurements (this occurs, for example, when shoulder width is plotted against height). 
For heart diameter against lung width the lines are straight and coincident within the limits of error. It seems that the spurt of the heart diameter and lung width occur equally and to the same extent in boys and girls.

In Fig. 16 and 17, however, the same is not true; lung length in girls appears to increase proportionately more in the last stages of growth than does heart diameter or lung width. This is not so in boys, in whom the lines continue quite straight. Further data are needed before we can be certain this is not a sampling error.

Lung width/lung length. Lung width was always greater than lung length except in two of the subjects (one on one occasion out of eight, the other on three occasions out of seven) where the reverse was the case. In neither of these two subjects was the diaphragm particularly low.

Diaphragm levels. Though the diaphragm level depends greatly on the phase of respiration and may therefore be of limited value in assessing growth, it was plotted to see whether there was any change during childhood and adolescence. It was striking that in girls, by the age of 18 , there was very much less variation of level than in boys of the same age or in younger children of either sex.

At the younger age groups the variation was wide. In girls age 6 the limits of the diaphragm level are midway between ribs 3 and 4 and between ribs 7 and 8 . In boys, at the same age, the limits are the 4th rib and the 7th rib-a narrower variation. At the age of 12 the variation is similar in boys and girls though the average values for boys are about half an intercostal space lower than for girls. In girls the variation is less than in the younger age group; the 97th centile falls at the intercostal space between the 6 th and 7 th ribs.

By the age of 20, the diaphragm was below the anterior end of the 5th rib in both males and females. In women no cases fell below the 6th rib, but in men $18 \%$ fell below it.

Individual variation in relation to centile. Of those subjects who had been radiographed between 5 and 15 years, 92 cases ( 46 of each sex) were studied to establish the pattern of centile change over the years. The male and female group behaved similarly. Of the 92 cases, only 10 did not cross a centile line at some time. Curves for 30 children, selected to provide 10 examples of each of the following types-those starting near the median value, those starting considerably above, and those considerably below it- were plotted on the standard curves. The same behaviour was found for these children as for the group as a whole.

\section{Discussion}

All the centile standards given are cross-sectionaltype standards; they do not allow for the differing ages at which the adolescent spurt occurs. Thus, when an individual child is followed through puberty he will be expected to increase his measurements more rapidly than these standards indicate. The truly average boy, for example, will begin to fall below the 50th centile in heart diameter at about 12 years, rise sharply to cross the 50th at about 14, and stay above the 50th until about 16 when he will have returned to it. (Illustrations of this for height longitudinal-type standards and a full discussion will be found in Tanner et al., 1966.) We cannot construct longitudinal-type standards of heart and lung measurements since, unfortunately, we have no data in these children that could give us a scale of developmental age, such as years before and after peak height velocity.

The velocity curves are subject to the same limitation, and for the same reason. Undoubtedly the adolescent spurt in a given individual is considerably more rapid than our mean curves indicate, since mixing children with early and late spurts results in the curve being stretched out along the horizontal axis and its peak diminished on the vertical axis. Probably the average child has a peak velocity $20-30 \%$ higher than the peaks given for the means in Fig. 11 to 14.

Comparison of the growth curves for boys and girls shows some distinctly unusual features. In heart diameter both sexes show an adolescent spurt of approximately equal magnitude. Nearly all other measurements show a greater spurt in boys, and skeletal muscles have of course a very much greater one in boys (Tanner, 1962, 1965, 1968).

The data of Maresh (1948, 1970) and Bliss and Young (1950) agree in showing adolescent spurts in boys and girls, but magnitudes of the peaks are rather less, being about $4 \mathrm{~mm} / \mathrm{yr}$ in boys and 3 $\mathrm{mm} / \mathrm{yr}$ in girls compared with our $5 \mathrm{~mm} / \mathrm{yr}$ in both sexes. The peaks are at 12 to 13 and $13 \frac{1}{2}$ to $14 \frac{1}{2}$. Before adolescence their values agree closely with ours, as do the figures of Lincoln and Spillman (1928).

Lung width has its spurt at the same time as heart diameter, height, and chest width, but lung length peaks some 6 months later, which coincides with the peaks of the anteroposterior chest diameter, or chest depth, as reported (Tanner, 1962, p. 12). 


\section{Growth of Radiologically Determined Heart Diameter, Lung Width, and Lung Length}

The lungs were unusual in their growth pattern. Not only were the magnitudes of the spurts in width and length similar in girls and boys, but in the Contact Clinic data the girls' measurements never equalled the boys', even at the age when they had finished their spurt and the boys were only just beginning theirs. (In the smaller Harpenden data, the girls surpassed the boys in lung length and just equalled them in lung width.) Even in limb muscle widths, which differ so greatly in adults, the girls equal or surpass boys at this time (Tanner, 1968). Only the feet (Chang, Chan, and Low, 1967) and head (Miklashevskaya, 1969) show a similar pattern, and in these measurements it is related to their relatively early development. However, lung development does not seem to be particularly advanced; at age 6 lung width is 66 to $67 \%$ (boys and girls) of adult value and length is 62 to $63 \%$ (boys and girls). This compares with figures for height of 66 to $67 \%$ (boys and girls). The early maturing foot length at age 6 is 70 to $74 \%$ (boys and girls) of adult. Heart diameter in our series, on the other hand, is relatively very advanced, with 6 -year values of 78 and $81 \%$ of adult, which is comparable to the face measurements. The Harpenden data agree with this.

Jeurissen (1959a, b, 1968) gives means and standard deviations for a number of lung measurements in girls. The lung width and lung length means show distinct adolescent spurts with peaks and highest standard deviations at age 12 to 13 years. In the same girls this coincides with the age at peak of stature and of hip width increase. There is a slight indication that in his data also the lung length peak occurs a few months later than the lung width peak. His lung length growth also agrees with ours in being a consistently lower percentage of adult value than is lung width-that is, it is a less advanced dimension.

The Sir Halley Stewart Trust made a grant in 1930 to found the Child Contact Clinic at the Brompton Hospital. Dr. W. E. Lloyd and Dr. Margaret Macpherson looked after it over the years and we are grateful to them for giving us access to these films. The Harpenden Growth Study was supported by the Ministry of Health and the Medical Research Council.

\section{REFERENCES}

Bliss, C. I., and Young, M. S. (1950). An analysis of heart measurements of growing boys. Human Biology, 22, 271.

Chang, K. S. F., Chan, S. T., and Low, W. D. (1967). Growth of the foot in Chinese children in Hong Kong. Far East Medical fournal, 3, 348.

Davies, P. D. B. (1961). The natural history of tuberculosis in children: a study of child contacts in the Brompton Hospital Child Contact Clinic from 1930 to 1952 . Tubercle, 42, Suppl.

Goldstein, H. (1970). Data processing for longitudinal studies. Applied Statistics, 19, 145.

Hiernaux, J. (1968). Bodily shape differentiation of ethnic groups and of the sexes through growth. Human Biology, 40, 44.

Jeurissen, A. (1959a). Téchnique de mensuration sur le sujet vivant du volume de la cage thoracique. Acta Tuberculosea et Pneumologica Belgica, 50, 346.

Jeurissen, A. (1959b). Le développement de la cage thoracique au cours de la croissance de la fillette et de la jeune fille. Acta Tuberculosea et Pneumologica Belgica, 50, 352.

Jeurissen, A. (1968). Capacité vitale et volume thoracique chez la fillette et la jeune fille. Biometrie Humaine, 3, 74.

Lincoln, E. M., and Spillman, R. (1928). Studies on the hearts of normal children. II. Roentgen-ray studies. American fournal of Diseases of Children, 35, 791.

Maresh, M. M. (1948). Growth of the heart related to bodily growth during childhood and adolescence. Pediatrics, 2, 382.

Maresh, M. (1970). Measurements from roentgenograms, heart size, long bone lengths, bone muscles and fat widths, skeletal maturation. In Human Growth and Development, p. 155. Ed. by Robert W. McCammon. Thomas, Springfield, Illinois.

Miklashevskaya, N. N. (1969). Sex differences in growth of the head and face in children and adolescents. Human Biology, 41, 250.

Patterson, H. D. (1950). Sampling on successive occasions with partial replacement of units. Fournal of the Royal Statistical Society, $B, 12,241$.

Simon, G. (1968). The limitations of the radiograph for detecting early heart enlargement. British fournal of Radiology, 41, 862 .

Tanner, J. M. (1962). Growth at Adolescence, 2nd ed. Blackwell, Oxford.

Tanner, J. M. (1965). Radiographic studies of body composition. In Body Composition (Symposia of the Society for the Study of Human Biology, Vol. 7), p. 211. Ed. by J. Brozek. Pergamon, Oxford.

Tanner, J. M. (1968). Growth of bone, muscle and fat during childhood and adolescence. In Growth and Development of Mammals. Ed. by G. A. Lodge and G. E. Lamming. Butterworth, London.

Tanner, J. M., Whitehouse, R. H., and Takaishi, M. (1966). Standards from birth to maturity for height, weight, height velocity, and weight velocity: British children, 1965. Part 1. Archives of Disease in Childhood, 41, 454.

Correspondence to Professor Lynne Reid, Department of Experimental Pathology, Institute of Diseases of the Chest, Brompton Hospital, London SW3. 